\title{
Françoise Le Borgne, Rétif de la Bretonne et la crise des genres littéraires (1767-1797)
}

\section{Paola Perazzolo}

\section{(2) OpenEdition}

1 Journals

\section{Edizione digitale}

URL: http://journals.openedition.org/studifrancesi/2166

DOI: 10.4000/studifrancesi.2166

ISSN: 2421-5856

\section{Editore}

Rosenberg \& Sellier

\section{Edizione cartacea}

Data di pubblicazione: 1 aprile 2014

Paginazione: 146-147

ISSN: 0039-2944

\section{Notizia bibliografica digitale}

Paola Perazzolo, «Françoise Le Borgne, Rétif de la Bretonne et la crise des genres littéraires (1767-1797)

", Studi Francesi [Online], 172 (LVIII | I) | 2014, online dal 01 avril 2014, consultato il 18 septembre 2020. URL : http://journals.openedition.org/studifrancesi/2166 ; DOI : https://doi.org/10.4000/

studifrancesi.2166

\section{Questo documento è stato generato automaticamente il 18 settembre 2020.}

\section{(c)}

Studi Francesi è distribuita con Licenza Creative Commons Attribuzione - Non commerciale - Non opere derivate 4.0 Internazionale. 


\title{
Françoise Le Borgne, Rétif de la Bretonne et la crise des genres littéraires (1767-1797)
}

\author{
Paola Perazzolo
}

\section{NOTIZIA}

FRANÇOISE LE BORGNE, Rétif de la Bretonne et la crise des genres littéraires (1767-1797), Paris, Champion, 2011, «Les Dix-Huitièmes Siècles», pp. 553.

1 Specialista riconosciuta di Rétif de la Bretonne, Françoise Le Borgne prende in considerazione la produzione singolare, abbondante ed eclettica dello stesso come esempio non unico ma particolarmente evidente di un nuovo approccio alla creazione letteraria. Tale mutamento rivela i cambiamenti estetici e sociologici in atto verso la fine del xviII secolo attraverso «le rejet explicite des genres classiques et la promotion de l'originalité, l'expérimentation de nouvelles pratiques d'écriture fondées sur la fragmentation et l'hybridation des formes, la volonté de concevoir une œuvre à son image et d'instaurer avec le lecteur un rapport de communion subjective» (p. 477). Il rifiuto della tradizione e dell'adesione alle norme poetiche classiche, l'affermazione della legittimità di una creazione originale risentono della volgarizzazione delle teorie empiriste cui Rétif aderisce, trovando così i fondamenti delle categorie estetiche non nella «norma» prestabilita ma nella natura umana, nel concetto di «goût» del singolo e, conseguentemente, in quello di «genio» che trova la sua ispirazione nell'esperienza e nella violenza delle passioni individuali. Questo spostamento del processo creativo sull'individuo - a livello di produzione così come di ricezione - sottende anche lo sviluppo di nuove forme artistiche, rese ora possibili anche dalla trasformazione del mercato dell'editoria e della stampa. Fin dall'inizio della sua carriera, Rétif si conforma ai gusti del cosiddetto grande pubblico: i primi romanzi epistolari di ambientazione inglese rivelano l'adesione alla moda del momento, le allusioni a opere di grandi autori testimoniano la volontà "opportunista" di sfruttare successi precedenti - è il caso, per 
esempio, del richiamo a Marivaux ne Le Paysan perverti del 1775 -, l'influenza dei periodici è evidente ne Les Nuits de Paris (1788-1794), così come la ripresa delle mode teatrali o narrative - $\mathrm{i}$ contes - vigenti in altre opere. L'interesse per i gusti del pubblico e le mode letterarie contemporanee, congiunto ad una volontà di smarcamento dai modelli ripresi, induce l'autore a una diversificazione delle pratiche di scrittura e a sperimentazioni che necessariamente prescindono dal concetto di «norma». Priva di riconoscimento ufficiale, l'opera trova così la sua legittimazione presso un lettore «oscuro» che permette la sussistenza di uno scrittore non inserito nel panorama letterario istituzionale, e che al contempo accredita la validità e la nascita di un nuovo status autoriale e di un rapporto autore/lettore inedito. Come spiega Le Borgne, Rétif si mostra come «un homme de lettres attentif au bien public, s'immolant à l'instruction de ses concitoyens et divulguant par ses écrits une vérité sociale et morale qui en fait tout le prix», di modo che «le simple citoyen, lecteur des ouvrages de Rétif, constitue [...] le pivot du dispositif affectif, moral et politique sur lequel repose la dignité littéraire de l'auteur» (p. 488).

Basato su un'imponente bibliografia primaria e secondaria, il presente volume offre un percorso dettagliato e preciso dell'opera poliedrica di Rétif de la Bretonne, considerato come uno tra i più paradigmatici esponenti di un mutamento che apre alla letteratura del secolo successivo per l'estrema valorizzazione dell'esperienza intima e individuale. Per Françoise Le Borgne, la produzione di Rétif si presenta come una sperimentazione particolarmente audace sotto vari punti di vista, contribuendo inoltre ad imporre modalità di ricezione originali che legittimano uno status autoriale che troverà la sua consacrazione nel decennio rivoluzionario, vera e propria «étape fondamentale dans le processus de décomposition des genres classiques» dal quale trarrà spunto e ragion d'essere tanta parte della letteratura del periodo seguente, e di quella romantica particolarmente (p. 491). 